\title{
Long-term follow-up is crucial after treatment for granulosa cell tumours of the ovary
}

\begin{abstract}
G Mangili ${ }^{*}, 1$, J Ottolina ${ }^{1}$, A Gadducci ${ }^{2}$, G Giorda ${ }^{3}$, E Breda ${ }^{4}$, A Savarese ${ }^{5}$, M Candiani ${ }^{1}$, L Frigerio ${ }^{6}$, G Scarfone ${ }^{7}$, S Pignata ${ }^{8}$, R Rossi ${ }^{9}$, M Marinaccio ${ }^{10}$ and D Lorusso ${ }^{11}$

${ }^{1}$ Gynecology Department, San Raffaele Scientific Institute, Via Olgettina 60, 20132 Milan, Italy; ${ }^{2}$ Procreative Medicine Department, Pisa University, Pisa, Italy; ${ }^{3}$ Gynecologic Oncology Department, National Cancer Institute, Aviano, Italy; ${ }^{4}$ Medical Oncology Department, San Giovanni Calibita-Fatebenefratelli Hospital, Isola Tiberina, Rome, Italy; ${ }^{5}$ Gynecologic Oncology Department, National Cancer Institute Regina Elena, Rome, Italy; ${ }^{6}$ Gynecology Department, Riuniti di Bergamo Hospital, Bergamo, Italy; 7Obstetrics and Gynecology Department, IRCCS Foundation Policlinico Mangiagalli Regina Elena Hospital, Milan, Italy; ${ }^{8}$ Gynecologic Oncology Department, National Cancer Institute, Naples, Italy; ${ }^{9}$ Obstetric and Gynecologic Department, Mazzoni Hospital, Ascoli Piceno, Italy; ${ }^{10}$ Gynecology Department, Bari I University, Bari, Italy and ${ }^{11}$ Gynecologic Oncology Department, Catholic University of the Sacred Heart, Rome/Campobasso, Italy
\end{abstract}

Objective: The aim of this study is to evaluate the long-term outcome of granulosa cell tumour (GCT) of the ovary in a large series of patients treated in MITO centres (Multicentre Italian Trials in Ovarian Cancer) and to define prognostic parameters for relapse and survival.

Methods: A retrospective multi-institutional review of patients with GCTs of the ovary treated or referred to MITO centres was conducted. Surgical outcome, intraoperative and pathological findings and follow-up data were analysed. Kaplan-Meier and Cox proportional hazards analyses were used to determine the predictors for survival and recurrence.

Results: A total of 97 patients with primary GCT of the ovary were identified. The median follow-up period was 88 months (range 6-498). Of these, 33 patients had at least one episode of disease recurrence, with a median time to recurrence of 53 months (range 9-332). Also, $47 \%$ of recurrences occurred after 5 years from initial diagnosis. At multivariate analysis, age and stage were independent poor prognostic indicators for survival; surgical treatment outside MITO centres and incomplete surgical staging retained significant predictive value for recurrence in both univariate and multivariate analyses.

Conclusions: This study confirms the generally favourable prognosis of GCTs of the ovary, with 5-year overall survival approaching $97 \%$. Nevertheless, prognosis after 20 years was significantly poorer, with 20 -year survival rate of $66.8 \%$ and a global mortality of 30-35. These findings support the need for lifelong follow-up even in early-stage GCT.

Ovarian granulosa cell tumours (GCTs) are an uncommon neoplasm that arise from the sex-cord stromal cells of the ovary and represent $2-5 \%$ of all ovarian cancers (Young, 2005).

These tumours are associated with a good prognosis because of early diagnosis and their not aggressive clinical behaviour. The long natural history of GCTs and their tendency to recur several years after the initial diagnosis are the most prominent of their characteristics (Sommers et al, 1955; Fox et al, 1975; Malmstrom et al, 1994).
Surgery is the mainstay of initial management and aims to achieve the histological diagnosis, an appropriate staging and a complete debulking of disease (Gershenson, 1994; National Comprehensive Cancer Network (NCCN) Guidelines, 2012). In patients with stage I disease and those in reproductive age, a more conservative unilateral salpingo-oophorectomy with peritoneal staging is indicated. In postmenopausal women and in those with more advanced disease, a total abdominal hysterectomy with bilateral salpingo-oophorectomy, peritoneal biopsies and removal

*Correspondence: Dr G Mangili; E-mail: mangili.giorgia@hsr.it

Received 6 February 2013; revised 16 April 2013; accepted 20 April 2013; published online 11 June 2013

(c) 2013 Cancer Research UK. All rights reserved 0007-0920/13 
of all visible disease is the appropriate surgical treatment (Colombo et al, 2007; Zhang et al, 2007).

Overall, the prognosis for women with GCT is quite good, with several authors reporting a 5-year survival rate of more than $90 \%$. The majority of women with adult GCT are diagnosed at stage I disease (80-90\%) and will therefore be expected to have a favourable outcome, but the presence of extraovarian disease correlates with a lower 5-year survival of 33-50\% (Evans et al, 1980).

Several factors of prognostic significance have been reported, but studies aiming at defining the prognostic factors have been frustrated not only by the relative rarity of these tumours but also by the very long period for which follow-up observation is required (Bjorkholm and Silfversward, 1981; Sehouli et al, 2004). The stage of disease is unequivocally the only prognostic factor associated with the risk of relapse (Stenwig et al, 1979; Miller et al, 1997; Lauszus et al, 2001).

The aim of the study is to evaluate the long-term outcome of GCT in a large series of patients treated in MITO (Multicenter Italian Trials in Ovarian Cancer) centres and to define the prognostic parameters for relapse and survival.

\section{MATERIALS AND METHODS}

The Multicentre Italian Trials in Ovarian Cancer (MITO)-9 is an Italian multicentre retrospective study aiming at describing clinical characteristics and treatment strategies of rare ovarian tumours.

A series of 97 patients diagnosed with primary GCTs of the ovary treated or referred after primary treatment to MITO centres from 1965 to 2008 were retrospectively analysed.

Patients were excluded if they had a concomitant diagnosis of another malignancy that was not a GCT or an endometrial carcinoma. In order to be included in the analysis, patients needed to have at least one clinical visit at either Institution with a review of their pathology at the corresponding Institution. In our population, $>95 \%$ of patients received continuative follow-up at MITO centres and $>50 \%$ of them have a longer than 10 years of follow-up.

Patients' data were recorded in a database that included information about age at diagnosis, clinical presentation, type of surgery, intraoperative findings and surgical outcome, stage, histology, adjuvant chemotherapy, relapse characteristics and relapse treatment and follow-up.

Surgery was the first treatment for all patients. A fertilitysparing surgery, defined as the preservation of the uterus and one ovary, was performed in young patients desiring to preserve fertility, only in case of disease confined to one ovary.

Radical surgery, including total abdominal hysterectomy, bilateral salpingo-oophorectomy and complete tumour debulking, was the standard procedure if fertility was not an issue.

Surgical staging was considered complete when including peritoneal washing, multiple peritoneal biopsies, omental biopsy and biopsy of any suspicious area. In case of conservative surgery, an endometrial biopsy to rule out a concomitant uterine disease was performed.

The staging system used for GCT is the same applied for epithelial ovarian cancer (International Federation of Gynaecology and Obstetrics (FIGO) staging system; FIGO Committee on Gynecologic Oncology, 2009). Patients with advanced-stage GCT (stages II, III and IV) received postoperative treatment.

All patients were incorporated in a prolonged surveillance program with periodic clinical, serologic and radiologic follow-up in a MITO centre, given the tendency of these tumours to recur several years after the initial diagnosis.

Written informed consent for anonymous publication of disease-related information is routinely obtained at MITO
Institutions during the medical interview with the patient preceding surgical or chemotherapy treatment.

Statistical analysis. Descriptive statistics were used to characterise the patient population. The clinicopathologic characteristics and treatment variables were evaluated for association with relapse or survival.

Follow-up period was measured from the date of primary diagnosis to the time of last follow-up visit.

Overall survival (OS) was defined as the time from the date of initial diagnosis to the date of death of any cause. Disease-free survival (DFS) was defined as the time period from the date of initial diagnosis to the first observation of recurrence. Overall survival and disease-free survival curves were estimated using the Kaplan-Meier method and were compared with the log-rank test.

Cox regression multivariate analysis was performed to identify independent predictors of recurrence and survival. Because $85 \%$ of patients presented with stage I disease (Jamieson and Fuller, 2008), the definition of prognostic factors for recurrence was carried out for stage I tumours.

In order to define prognostic parameters for relapse and survival, variables regarding patients' characteristics were dichotomised in the following manner: age $<50$ or $>50$ years; juvenile GCT subtype $v s$ adult GCT histology; tumour size measuring $<10$ or $>10 \mathrm{~cm}$; primary surgery at Mito centres or elsewhere; conservative $v s$ radical surgery; laparoscopic $v s$ laparotomic approach; complete staging $v s$ incomplete staging; residual disease at first surgery $v s$ no residual disease; execution of lymphadenectomy vs no lymph nodal dissection; stage I of disease $v s$ advanced stage of disease; adjuvant treatment $v s$ no postsurgery treatment.

Variables with $P<0.05$ on univariate analysis were selected for multivariate analysis.

Differences were considered statistically significant at $P<0.05$.

The SPSS statistical software program (SPSS Inc., Chicago, IL, USA) was used.

\section{RESULTS}

Patients' characteristics. A total of 97 patients with primary adult GCTs of the ovary were evaluated for the present analysis. Median age of all patients was 51 years (range: $27-82$ ), and in particular 48 women $(49.5 \%)$ were $<50$ years old.

The most common presenting symptom was the presence of a mass and/or abdominal distension that was observed in 49 patients (50.5\%); 29 patients (28.9\%) presented with abdominal and/or pelvic pain, 25 patients $(25.8 \%)$ presented with menstrual irregularities, whereas only 5 patients $(5.2 \%)$ had ascites at the time of initial diagnosis. In addition, 6 patients $(6.2 \%)$ presented with concurrent endometrial carcinoma and 17 (17.5\%) had endometrial hyperplasia.

Surgery represented the first approach to the disease for all the study population; 64 (66\%) patients received surgical treatment in MITO centres, whereas 33 (34\%) were operated on elsewhere and then referred in the postoperative setting for subsequent evaluation or for recurrence.

The approach was laparoscopic in 23 patients $(23.7 \%)$ and laparotomic in the remaining population.

Fertility-sparing surgery was performed in 24 patients $(24.7 \%)$, whereas 73 patients (75.3\%) underwent radical surgery. Overall, 42 patients $(43.3 \%)$ were incompletely surgically staged at initial diagnosis; complete surgical staging was performed in 55 patients (56.7\%), all of them treated at MITO centres.

Complete surgical tumour excision was obtained in $95.9 \%$ of patients. In all, 15 patients (15.5\%) had a pelvic lymph node sampling; 8 patients $(8.2 \%)$ also had a paraaortic lymph node 
sampling performed during primary surgery; in all cases, pelvic and paraaortic lymph nodes removed were negative for metastatic CCTs.

The FIGO stage distribution was as follows: 70 patients $(72.2 \%)$ presented with stage I disease, including 47 patients at stage Ia, 3 at stage $\mathrm{Ib}$ and 20 at stage Ic; 11 patients were defined as 'apparent stage I of disease' (stage Ix); stage II, 6 patients (6.2\%); stage III, 8 patients $(8.2 \%)$; stage IV, 2 patients (2.1\%).

The MITO group did not provide guidelines regarding clinical management; nevertheless, in our population, 23 patients received platinum-based chemotherapy: 13 were at stage I disease, 3 at stage II, 7 at stage III and 2 at stage IV. These patients received postoperative systemic treatment mainly with the combination regime bleomycin, etoposide and cisplatin $(n=16)$, or platinumbased regimen in a minority of cases $(n=7)$.

In addition, two patients were treated with postsurgery radiotherapy.

Postoperative. Treatment strategies and clinicopathological characteristics are reported in Table 1.

Patients' outcomes. The median follow-up period was 88 months (range 6-498). A total of 33 patients had at least one episode of disease recurrence, with a median time to recurrence of 53 months (range 9-332).

In all, $54 \%$ of recurrences occurred within 5 years from diagnosis; $39 \%$ of patients recurred from 5 to 10 years after

Table 1. Treatment strategies and clinicopathological characteristics

\begin{tabular}{|c|c|}
\hline Characteristics & Number of patients, $n(\%)$ \\
\hline \multicolumn{2}{|l|}{ Age of diagnosis } \\
\hline $\begin{array}{l}\text { Mean (years) } \\
\leqslant 50 \text { Years } \\
>50 \text { Years }\end{array}$ & $\begin{array}{l}52.02 \text { (range 27-82) } \\
\quad 48(49.5) \\
49(50.5)\end{array}$ \\
\hline \multicolumn{2}{|l|}{ Stage at diagnosis } \\
\hline $\begin{array}{l}\text { Stage I } \\
\text { Apparent stage I (Ix) } \\
\text { Stage II } \\
\text { Stage III } \\
\text { Stage IV }\end{array}$ & $\begin{array}{c}70(72.2) \\
11(11.3) \\
6(6.2) \\
8(8.2) \\
2(2.1)\end{array}$ \\
\hline \multicolumn{2}{|l|}{ Surgery } \\
\hline $\begin{array}{l}\text { Fertility-sparing } \\
\text { Radical }\end{array}$ & $\begin{array}{l}24(24.7) \\
73(75.3)\end{array}$ \\
\hline \multicolumn{2}{|l|}{ Surgery } \\
\hline $\begin{array}{l}\text { Laparoscopy } \\
\text { Laparotomy }\end{array}$ & $\begin{array}{l}23(23.7) \\
74(76.3)\end{array}$ \\
\hline \multicolumn{2}{|l|}{ Surgery } \\
\hline $\begin{array}{l}\text { Lymphadenectomy } \\
\text { No lymphadenectomy }\end{array}$ & $\begin{array}{l}15(15.5) \\
82(84.5)\end{array}$ \\
\hline \multicolumn{2}{|l|}{ Surgery } \\
\hline $\begin{array}{l}\text { MITO } \\
\text { Elsewhere }\end{array}$ & $\begin{array}{l}64(66) \\
33(34)\end{array}$ \\
\hline \multicolumn{2}{|l|}{ Adjuvant treatment } \\
\hline $\begin{array}{l}\text { No adjuvant treatment } \\
\text { Chemotherapy } \\
\text { Radiation }\end{array}$ & $\begin{array}{c}72(74.2) \\
23(23.7) \\
2(2.1)\end{array}$ \\
\hline
\end{tabular}

diagnosis; $6 \%$ of patients experienced relapse after more than 20 years from initial diagnosis.

Particularly, patients at advanced stage of disease (stages II, III and IV) recurred in $43 \%$ of cases within 5 years from diagnosis and in $57 \%$ of cases between 5 and 10 years after diagnosis. On the contrary, stage Ia patients experienced relapse later: $20 \%$ of patients recurred more than 20 years from diagnosis (Figure 1).

Pelvic and abdominal recurrences were the primary sites of failure in $72.8 \%$ of cases and only $12 \%$ of first recurrences appeared to involve the retroperitoneum.

The distribution of recurrences according to the stage of disease was as follows: 20 out of $80(25 \%)$ patients at stage I, 6 out of 11 (54\%) patients at stage Ix, 1 out of $6(16 \%)$ patients at stage II, 5 out of $8(62 \%)$ patients at stage III and 1 out of $2(50 \%)$ patient at stage IV.

At recurrence, 25 patients underwent debulking surgery plus chemotherapy, 6 patients had only surgical cytoreduction and 2 patients received surgery plus radiotherapy. In all patients, a histologic confirmation of GCT was achieved.

At the time of last follow-up, 5 patients (4.7\%) had died of disease, 6 patients (5.6\%) were alive with evidence of disease, 80 patients $(74.8 \%)$ were alive with no evidence of disease, 14 patients (13.1\%) were lost to follow-up and 2 deaths (1.9\%) were considered related to other causes.

After excluding non-GCT-related death, the estimated OS after 5 and 10 years was $97 \%$ and $95 \%$, respectively; the 5-year and 10 year DFS rate was $91.8 \%$ and $71.6 \%$, respectively.

Among the 33 relapsed patients, 18 patients (54.5\%) are alive with no evidence of disease, 5 patients $(15.2 \%)$ are alive with disease, 5 patients $(15.2 \%)$ died of disease, 1 patient (3\%) died because of other causes and 4 patients $(12.1 \%)$ are lost at follow-up. Median survival after recurrence is 72 months (range 1-207).

Prognostic factors. Univariate and multivariate regression analyses were performed to evaluate the influence of different clinicopathologic characteristics and treatment strategies on DFS and OS.

Prognostic factors are reported in Table 2.

Older age at diagnosis ( $>50$ years), advanced stage of disease and residual tumour at the end of surgery were associated with a poor prognosis. At multivariate analysis, age $(\mathrm{RR}=5.52 ; 95 \%$ $\mathrm{CI}=2.42-6.86)$ and stage $(\mathrm{RR}=10.25 ; 95 \% \mathrm{CI}=8.21-16.64)$ were independent poor prognostic indicators for survival.

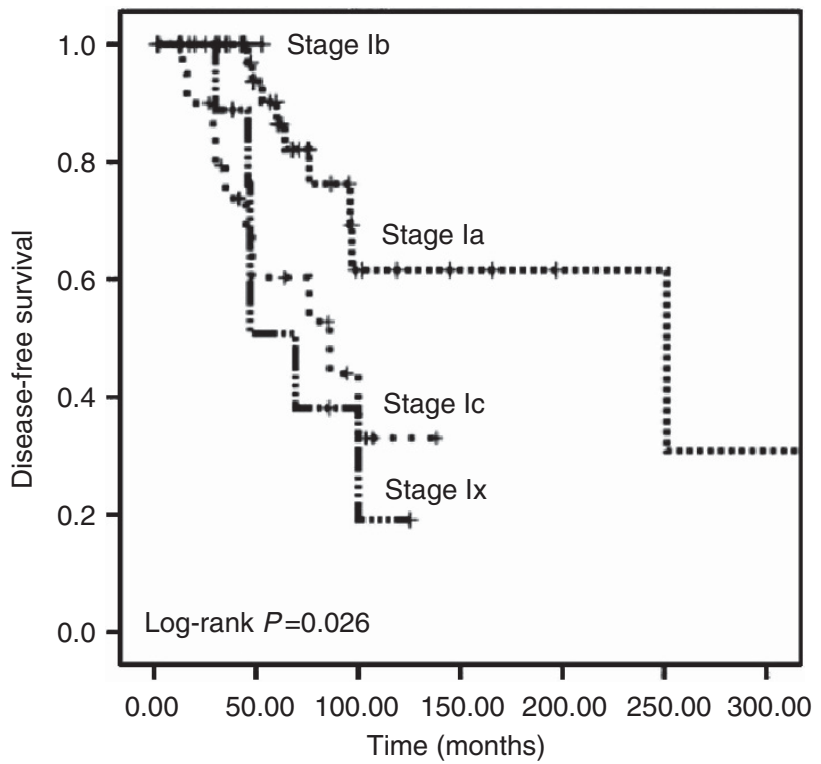

Figure 1. Kaplan-Meier disease-free survival for stage I disease. 


\begin{tabular}{|l|c|c|c|c|}
\hline \multicolumn{4}{|c|}{ Table 2. Prognostic factors for survival in granulosa cell tumours } \\
\cline { 2 - 5 } & \multicolumn{2}{|c|}{$\begin{array}{c}\text { Univariate } \\
\text { analysis }\end{array}$} & $\begin{array}{c}\text { Multivariate } \\
\text { analysis }\end{array}$ \\
\hline Factor & P-value & RR & P-value & RR \\
\hline Age $>50$ years & 0.004 & 5.86 & 0.009 & 5.52 \\
\hline Stage at diagnosis (I-II vs III-IV) & 0.006 & 10.57 & $<0.001$ & 10.25 \\
\hline Number of mitosis & 0.62 & & NS & \\
\hline Histology & 0.23 & & NS & \\
\hline MITO/elsewhere & 0.14 & & NS & \\
\hline Surgical approach & 0.18 & & NS & \\
\hline Complete staging/unstaged & 0.25 & & NS & \\
\hline Lymphadenectomy & 0.94 & & NS & \\
\hline Residual disease at first surgery & 0.45 & & NS & \\
\hline Adjuvant treatment & 0.62 & & NS & \\
\hline Tumour size & 0.91 & & NS & \\
\hline Abbreviations: MITO=Multicentre Italian & Trials in & Ovarian & Cancer centre; NS=not \\
significant; RR= relative risk. & & & & \\
\hline
\end{tabular}

\begin{tabular}{|c|c|c|c|c|}
\hline Factor & $\begin{array}{l}\text { Recurrence } \\
\text { rate (\%) }\end{array}$ & $\begin{array}{c}\text { Univariate } \\
\boldsymbol{P} \text {-value }\end{array}$ & $\begin{array}{c}\text { Multivariate } \\
\boldsymbol{P} \text {-value }\end{array}$ & OR \\
\hline $\begin{array}{l}\text { Primary surgery } \\
\text { outside MITO centre }\end{array}$ & 59 & $<0.001$ & $<0.001$ & 3.32 \\
\hline $\begin{array}{l}\text { Primary surgery in } \\
\text { MITO centre }\end{array}$ & 22 & & & \\
\hline Laparotomy approach & 34 & 0.05 & NS & \\
\hline $\begin{array}{l}\text { Laparoscopy } \\
\text { approach }\end{array}$ & 13 & & & \\
\hline Conservative surgery & 33 & NS & & \\
\hline Radical surgery & 26 & & & \\
\hline Complete staging & 20 & 0.030 & 0.009 & 1.23 \\
\hline Unstaged & 39 & & & \\
\hline Adjuvant treatment & 27 & NS & & \\
\hline $\begin{array}{l}\text { No adjuvant } \\
\text { treatment }\end{array}$ & 29 & & & \\
\hline Lymphadenectomy & 40 & NS & & \\
\hline No lymphadenectomy & 28 & & & \\
\hline $\begin{array}{l}\text { Abbreviations: } \mathrm{MITO}=N \\
\text { significant; } O R=\text { odds rat }\end{array}$ & entre Italian & $s$ in Ovarian & Cancer centre; & $S=$ not \\
\hline
\end{tabular}

Histology, number of mitosis, mass diameter, surgical approach (laparoscopy vs laparotomy), surgical staging, lymphadenectomy, treatment in a referral tertiary centre and postoperative treatment were not statistically significantly associated with death.

The 5 -year OS rates were $99 \%$ and $95 \%$ for patients $<50$ and $>50$ years old (log-rank test, $P=0.036$ ).

The 5 -year OS rates were $98.7 \%$ and $75 \%$ for patients with stage I-II and III-IV, respectively (log-rank test, $P<0.001$ ).

Table 3 shows the association of clinicopathologic factors with DFS in patients with stage I disease.

Surgical treatment outside MITO centre (OR $=3.32 ; 95 \%$ $\mathrm{CI}=1.35-8.15)$ and incomplete surgical staging $(\mathrm{OR}=1.23 ; 95 \%$
$\mathrm{CI}=1.02-2.28)$ retained significant predictive value for recurrence in both univariate and multivariate analyses.

Surgical approach (laparoscopy vs laparotomy), type of surgery (conservative $v s$ radical), execution of adjuvant chemotherapy and performance of lymphadenectomy were not associated with recurrence.

\section{DISCUSSION}

Granulosa cell tumors of the ovary are considered as low-grade malignancies with a relatively more favourable prognosis when compared with the more common epithelial ovarian tumours (Healy et al, 1993; Sehouli et al, 2004). Despite this generally favourable clinical behaviour, a certain percentage of patients diagnosed with GCT still suffer from recurrence and diseaserelated mortality (Ranganath et al, 2008); unfortunately, not only the rarity of GCT, but also its slow progression and the long time period for which follow-up observation is required, make it difficult to clearly understand the clinical course of the disease, provide adequate treatment guidelines and recognise the prognostic factors for recurrence and death.

In most of the studies, stage of disease, tumour size, tumour rupture, age at diagnosis, nuclear atypia, mitotic index, surgical method and presence of residual disease after initial surgery were shown to be important prognostic factors in GCTs (Bjorkholm and Silfversward, 1981; Lauszus et al, 2001; Ayhan et al, 2009; Iyibozkurt et al, 2010; Thrall et al, 2011); however,, most of these studies consist of a limited number of patients because of the rarity of the disease, and thus do not allow us to draw definitive conclusions on prognostic factors.

In this study we analysed the clinical data of 97 patients with adult GCT of the ovary treated in MITO centres. Stage of disease, age of patients, presence of macroscopic residual disease, use of adjuvant treatment, complete surgical staging and performance of lymphadenectomy were investigated in order to investigate their prognostic significance.

Stage is currently the widest approved prognostic factor of GCT (Fox et al, 1975; Bjorkholm and Silfversward, 1981; Miller et al, 1997). The 5-year survival is reported to be $75-95 \%$ for patients with early-stage disease (Fox et al, 1975; Schumer and Cannistra, 2003) and declined to $25-50 \%$ in patients with advanced disease (Stenwig et al, 1979; Bjorkholm and Silfversward,1981). Similarly, in the current series, we found that patients with stage I-II disease had a survival advantage of $25 \%$ compared with those with stage III-IV, hence indicating that the stage is an independent predictor of survival. In comparison with the previously published studies (Fox et al, 1975; Schumer and Cannistra, 2003), in our series the follow-up is longer and, as such, is able to detect more delayed recurrences, thus justifying the longer time interval to recurrences that we reported in comparison with other series.

The prognostic significance of age in GCTs is controversial. In the two larger studies reported in the literature, both having $>90$ patients, younger age was associated with a survival advantage, but the favourable threshold was highly variable (Stenwig et al, 1979; Schumer and Cannistra, 2003; Zhang et al, 2007; Park et al, 2012). In this series of 97 women, patients $<50$ years had a $9 \%$ survival advantage over their older cohorts; age is a significant prognostic variable at multivariate analysis in conjunction with disease stage.

Residual disease after surgery may also affect oncologic prognosis adversely (Malmstrom et al, 1994; Lee et al, 2008): residual tumour was clearly associated with a poor prognosis in our study, but this finding was no longer relevant in multivariate analysis after accounting for stage and age at diagnosis.

As previously reported by other authors (Park et al, 2012), in our series lymphadenectomy was not an independent prognostic 
factor for recurrence and survival and, given the absence of positive nodes at first surgical approach and the low rate of involvement of lymph nodes at recurrence (12\%), we could conclude that surgical staging of GCT should not be extended to the retroperitoneum.

In accordance with what was previously described in literature, among our patients 6 presented with concomitant endometrial carcinoma and 17 with hyperplasia, further underlying the necessity to take a biopsy of the endometrium during conservative procedures in order to exclude a concomitant neoplasia.

In our study adjuvant chemotherapy seems not to represent a protective factor for recurrence or death; some authors (Colombo et al, 2007) have advocate the use of chemotherapy in the adjuvant setting of advanced-stage disease as well as in high-risk, early-stage patients (large tumour size, high mitotic index, tumour rupture or incomplete surgical staging), but our data seem not to support this recommendation. Giving the retrospective nature of the trial, we have no data on why stage I tumours received adjuvant chemotherapy; further studies with more elevated numbers of patients are warranted to better elucidate this issue.

Granulosa cell tumours are classified as a malignant tumour with a long natural history and a tendency for late recurrence; although an indolent course, $\sim 80 \%$ of patients with recurrent GCT die because of the disease (Jamieson and Fuller, 2008).

Several risk factors for recurrence after surgery for GCT have been suggested, including advanced age, large tumour size, advanced stage at diagnosis, tumour rupture, lymphatic space invasion, nuclear atypia and high mitotic index (Lee et al, 2008; Iyibozkurt et al, 2010; Thrall et al, 2011).

Initial treatment not in a referral MITO centre seems to be an independent risk factor for recurrence in our series: this result may represent the epiphenomenon of a suboptimal surgical treatment, or of an inaccurate pathological analysis, or of a delayed beginning of adjuvant treatment in high-risk patients.

Similarly, incomplete surgical staging was significantly associated with DFS at multivariate analysis in patients with early-stage GCT. Park et al (2012) had previously highlighted the role of staging procedures, showing survival benefits from complete surgical staging in patients with presumed I-II stages GCT, without arriving to identify an independent prognostic factor.

Recurrence of GCT is not a rare event: previous papers have reported a relapse rate among GCT ranging from 17 to $50 \%$ (Miller et al, 1997; Lauszus et al, 2001; Lee et al, 2008). This wide range is probably related to the extremely different follow-up period reported in the studies; GCT in fact is a typically late relapse disease in which the recurrence rate seems to increase in a timedependent manner, and therefore long-time follow-up is necessary in order to obtain reliable data regarding the natural history of GCT.

In our series, the median follow-up period was 88 months (range 6-498), which is significantly longer than in other recently published studies (Pecorelli et al, 1999), and the recurrence rate we registered was $30.8 \%$, which can be considered realistic and representative of the natural history of the disease.

Recurrent disease occurred after a median of 53 months (range 9-332) in our study; several studies reported an average diseasefree survival of 5-10 years (Evans et al, 1980; Lauszus et al, 2001), with recurrences diagnosed more than 30 years after the initial treatment (Ifaturoti and Crocker, 2004). The longest recurrencefree interval in our study was 27.6 years, suggesting that, even after a disease-free interval of 20 years, we could not consider the patient definitively cured without any chance of recurrence.

Moreover, $20 \%$ of patients with stage I disease recurred after 20 years from diagnosis, supporting the idea that lifelong follow-up throughout a patient's life is needed even in early-stage GCT and that for more than three decades, GCT should be considered malignant. In the absence of strong evidences on follow-up strategy in GCT, we refer to ESMO guidelines recommending pelvic examination and tumour markers every 3 months for the first 2 years, and then every 6 months after the third year until progression; a pelvic ultrasound should be carried out every 6 months in those patients who have undergone fertility-sparing surgery, whereas a CT scan of the abdomen and pelvis is usually carried out according to clinical indication (Colombo et al, 2012).

In conclusion, we could confirm the generally favourable prognosis of GCTs of the ovary, with 5-year overall survival approaching 97\%; these patients tend to have early-stage disease as reflected by the $85 \%$ of women with stage I disease in our population. Nevertheless, prognosis after 20 years was significantly poorer, with 20 -year survival rate of $66.8 \%$ and a global mortality of 30-35.

This study has the limitations that are inherent in retrospective studies. This series covers almost 40 years and it is likely that temporal change in practice patterns increases the difficulty of evaluating outcomes according to the provided care.

The current literature on ovarian GCTs consists mainly of reports with small number of patients; the strongest aspects of our study include the large number of enrolled patients and the longterm follow-up, which allows us to maximise our ability to identify recurrent disease prognostic factors.

\section{ACKNOWLEDGEMENTS}

We thank the investigators participating in this study. The MITO-9 Institutions participating in the study are listed as follows: IRCCS San Raffaele Hospital, Milan, Italy; Catholic University of the Sacred Heart, Rome/ Campobasso, Italy; Pisa University, Pisa, Italy; National Cancer Institute, Aviano, Italy; National Cancer Institute Regina Elena, Rome, Italy; San Giovanni CalibitaFatebenefratelli Hospital, Isola Tiberina, Rome, Italy; Riuniti di Bergamo Hospital, Bergamo, Italy; IRCCS Foundation Policlinico Mangiagalli Regina Elena Hospital, Milan, Italy; Federico II University of Naples, Naples, Italy; National Cancer Institute, Naples, Italy; University of Bari I, Bari, Italy; University of Bari II, Bari, Italy; IRCCS Foundation Policlinico San Matteo, Pavia, Italy; Hospital of Faenza, Faenza, Italy; Mazzoni Hospital, Ascoli Piceno, Italy; Santa Maria della Misericordia Hospital, University of Perugia, Perugia, Italy; University of Rome 'Campus Bio-Medico,' Rome, Italy.

\section{CONFLICT OF INTEREST}

The authors declare no conflict of interest.

\section{REFERENCES}

Ayhan A, Salman MC, Velipasaoglu M, Sakinci M, Yuce K (2009) Prognostic factors in adult granulose cell tumors of the ovary: a retrospective analysis of 80 cases. J Gynecol Oncol 20: 158-163.

Bjorkholm E, Silfversward C (1981) Prognostic factors in granulosa-cell tumors. Gynecol Oncol 11: 261-274.

Colombo N, Parma G, Zanagnolo V, Insinga A (2007) Management of ovarian stromal cell tumors. J Clin Oncol 25: 2944-2951.

Colombo N, Peiretti M, Garbi A, Carinelli S, Marini C, Sessa C (2012) Non-epithelial ovarian cancer: ESMO Clinical Practice Guidelines for diagnosis, treatment. Ann Oncol 23(7): 20-26.

Evans IIIAT, Gaffey TA, Malkasian Jr GD, Annegers JF (1980) Clinicopathologic review of 118 granulosa and 82 theca cell tumors. Obstet Gynecol 55: 231-238.

FIGO committee on gynecologic oncology (2009) Current FIGO staging for cancer of the vagina, fallopian tube, ovary and gestational trophoblastic neoplasia. Int J Gynaecol Obstet 105(1): 3-4. 
Fox H, Agrawal K, Langley FA (1975) A clinicopathologic study of 92 cases of granulosa cell tumor of the ovary with special reference to the factors influencing prognosis. Cancer 35(1): 231-241.

Gershenson DM (1994) Management of early ovarian cancer: germ cell and sex cord-stromal tumors. Gynecol Oncol 55(3 Pt 2): S62-S72.

Healy DL, Burger HG, Mamers P, Jobling T, Bangah M, Quinn M, Grant P, Day AJ, Rome R, Campbell JJ (1993) Elevated serum inhibin concentrations in postmenopausal women with ovarian tumors. $N$ Engl J Med 329: 1539-1542.

Ifaturoti O, Crocker SG (2004) Ovarian granulosa cell tumor recurring 36 years after primary treatment. J Obstet Gynaecol 24: 331-332.

Iyibozkurt AC, Topuz S, Gungor F, Akhan SE, Demirci F, Salihoglu Y, Berkman S, Bengisu E (2010) Factors affecting recurrence and disease-free survival in granulosa cell tumors of the ovary. Eur J Gynaecol Oncol 31: 667-671.

Jamieson S, Fuller PJ (2008) Management of granulosa cell tumour of the ovary. Curr Opin Oncol 20: 560-564.

Lauszus FF, Petersen AC, Greisen J, Jakobsen A (2001) Granulosa cell tumor of the ovary: a population-based study of 37 women with stage I disease. Gynecol Oncol 81(3): 456-460.

Lee YK, Park NH, Kim JW, Song YS, Kang SB, Lee HP (2008) Characteristics of recurrence in adult-type granulose cell tumor. Int J Gynecol Cancer 18: 642-647.

Malmstrom H, Hogberg T, Risberg B, Simonsen E (1994) Granulosa cell tumors of the ovary: prognostic factors and outcome. Gynecol Oncol 52(1): 50-55.

Miller BE, Barron BA, Wan JY, Delmore JE, Silva EG, Gershenson DM (1997) Prognostic factors in adult granulosa cell tumor of the ovary. Cancer 79(10): 1951-1955.

National Comprehensive Cancer Network (NCCN) guidelines (2012) Available at www.nccn.org. Accessed on 15 May 2012.

Park JY, Jin KL, Kim DY, Kim JH, Kim YM, Kim KR, Kim YT, Nam JH (2012) Surgical staging and adjuvant chemotherapy in the management of patients with adult granulose cell tumors of the ovary. Gynecol Oncol 125: 80-86.

Pecorelli S, Wagenaar HC, Vergote IB, Wagenaar HC, Vergote IB, Curran D, Beex LV, Wiltshaw E, Vermorken JB (1999) Cisplatin (P), vinblastine (V) and bleomycin (B) combination chemotherapy in recurrent or advanced granulose (-theca) cell tumors of the ovary. An EORTC Gynaecological Cancer Cooperative Group study. Eur J Cancer 35(9): 1331-1337.

Ranganath R, Sridevi V, Shurkey SS, Shanta V (2008) Clinical and pathologic prognostic factors in adult granulosa cell tumors of the ovary. Int J Gynecol Cancer 18: 929-933.

Schumer ST, Cannistra SA (2003) Granulosa cell tumor of the ovary. J Clin Oncol 21: 1180-1189.

Sehouli J, Drescher FS, Mustea A, Elling D, Friedmann W, Kühn W, Nehmzow M, Opri F, Klare P, Dietel M, Lichtenegger W (2004) Granulosa cell tumor of the ovary: 10 years follow-up data of 65 patients. Anticancer Res 24: 1223-1229.

Sommers SC, Gates O, Goodof II (1955) Late recurrence of granulosa cell tumors; report of two cases. Obstet Gynecol 6(4): 395-398.

Stenwig JT, Hazekamp JT, Beecham JB (1979) Granulosa cell tumors of the ovary. A clinicopathological study of 118 cases with long-term follow up. Gynecol Oncol 7: 136-152.

Thrall MM, Paley P, Pizer E, Garcia R, Goff BA (2011) Patterns of spread and recurrence of sex-cord stromal tumors of the ovary. Gynecol Oncol 122: $242-245$.

Young RH (2005) Sex cord-stromal tumors of the ovary and testis: their similarities and differences with consideration of selected problems. Mod Pathol 18(Suppl 2): S81-S98.

Zhang M, Cheung MK, Shin JY, Kapp DS, Husain A, Teng NN, Berek JS, Osann K, Chan JK (2007) Prognostic factors responsible for survival in sex cord stromal tumors of the ovary-an analysis of 376 women. Gynecol Oncol 104: 396-400.

This work is published under the standard license to publish agreement. After 12 months the work will become freely available and the license terms will switch to a Creative Commons AttributionNonCommercial-Share Alike 3.0 Unported License. 